\title{
SISTEM PENGOLAHAN DATA KLIEN DAN DOKUMEN PADA IRNA ROCHA, SH MENGGUNAKAN VISUAL BASIC.NET
}

\author{
Mori Valentina ${ }^{1}$, Asparizal ${ }^{2}$, Teuku Radillah ${ }^{3}$ \\ ${ }^{1,2,3}$ Sekolah Tinggi Manajemen Informatika \& Komputer ( STMIK ) Dumai \\ Jln. Utama Karya Bukit Batrem Dumai-Riau Kode Pos 28811 \\ E-mail : mori_valentina14@ymail.com
}

\begin{abstract}
ABSTRAK
Penelitian telah di lakukan pada PPAT Irna Rocha, SH Dumai dimana permasalahan yang dijadikan dasar dalam penelitian ini yaitu pengolahan data klien dan dokumen yang masih dilakukan secara manual. Sehingga hal ini dapat mengurangi efesiensi dalam bekerja. Oleh karena itu, dirancang lah sebuah aplikasi data klien dan dokumen sebagai solusi terhadap masalah yang dihadapi bagian administrasi di PPAT Irna Rocha,SH Dumai tersebut. Manfaat Terbesar dari perancangan aplikasi ini adalah agar dapat mempermudah pengguna dalam melakukan pengolahan data agar dapat melakukan pencarian data-data yang dibutuhkan dalam waktu yang relatif singkat serta dapat menghasilkan laporan yang terjadwal. Dimana aplikasi ini dirancang menggunakan bahasa pemrograman Visual Basic.Net 2008 dengan MySql sebagai databasenya crystal report untuk membuat laporannya.
\end{abstract}

Kata Kunci : Sistem, Pengolahan Data, Klien, Dokumen

\section{PENDAHULUAN}

PPAT Irna Rocha, SH merupakan perusahaan yang bergerak dalam bidang jasa pembuatan akta. Sistem pengolahan data Klien dan dokumen pada PPAT Irna Rocha, SH masih menggunakan Microsoft Excel dan belum ada aplikasi yang digunakan dalam pengolahan data klien dan dokumen berbasis database.

Dalam hal ini, bagian administrasi sering mengalami kesulitan dalam pembuatan laporan data klien dan dokumen belum terstruktur dan belum secara priodik, sehingga tidak efektif dan tidak efisien. Selain dalam pembuatan laporan data klien dan dokumen, ada juga beberapa kendala yang di alami oleh bagian administrasi seperti, sering terjadi redudansi data klien dan dokumen, serta membutuhkan waktu yang lama dalam pencarian data klien dan dokumen.

Untuk itulah PPAT Irna Rocha, SH memerlukan sebuah sistem pengolahan data klien dan dokumen yang berbasis komputer dan sebuah database untuk dapat menampung data dalam jumlah banyak serta dapat Meningkatkan efektifitas dan efesiensi kerja dalam pembuatan laporan data klien dan dokumen
Berdasarkan latar belakang masalah diatas, maka dapat di identifikasikan masalah yang akan diteliti adalah sebagai berikut :

1. Belum ada aplikasi yang digunakan dalam pengolahan data klien dan dokumen berbasis database.

2. Sistem pengolahan data klien dan dokumen masih menggunakan microsoft excel.

3. Sering terjadi redudansi data klien dan dokumen.

4. Membutuhkan waktu yang lama dalam pencarian data klien dan dokumen.

5. Pembuatan laporan data klien dan dokumen belum terstruktur dan belum secara priodik, sehingga tidak efektif dan tidak efisien.

Berdasarkan identifikasi masalah di atas, perumusan masalah yang diambil dalam melakukan penelitian pada PPAT Irna Rocha, SH yaitu "Bagaimana merancang Sistem Pengolahan Data Klien dan Dokumen yang dapat memberikan kemudahan kepada pihak PPAT dalam penyimpanan data klien dan dokumen, dan dapat menghasilkan informasi laporan data klien dan dokumen yang akurat".

Ruang lingkup penelitian ini meliputi hal berikut ini : 
I N F ORM I T I K

Jurnal Informatika, Manajemen dan Komputer, Vol. 8 No. 2 , Desember 2016

eISSN : 2580-3042

pISSN : 1979-0694

1. Pada penelitian ini hanya membahas masalah pengolahan data data klien, input data akta, input data hak, input data biaya dan input data pembuatan akta

2. Bahasa pemograman yang digunakan adalah Visual Basic Net

3. Database yang digunakan adalah MySQL Versi 5.1.3 dan aplikasi Xampp

Adapun Tujuan dari Penelitian adalah sebagai berikut :

1. Penyimpanan data klien dan dokumen menjadi lebih efektif.

2. Pencarian data klien dan dokumen menjadi lebih mudah menggunakan komputerisasi.

3. Meningkatkan efektifitas dan efesiensi kerja dalam pembuatan laporan data klien dan dokumen.

4. Merancang sistem pengolahan data klien dan dokumen dengan menggunakan database, yang selama ini masih menggunakan microsoft excel.

\section{a. PengertianPengolahan Data}

Data dalah kenyataan yang menggambarkan suatu kejadian-kejadian dan kesatuan nyata. Kejadian-kejadian adalah sesuatu yang terjadi pada saat tertentu di dalam dunia bisnis (Tata Sutabri, 2012:h.1)

Menurut Jogiyanto (2009:h.3). Suatu Proses pengolahan data terdiri atas 3 tahap dasar, yang disebut dengan siklus pengolahan data (processing cycle), yaitu input, processing dan ouput.

\section{b. Analisis Sistem}

Analisis sistem merupakan tahapan paling awal dari pengembangan sistem yang menjadi fondasi menentukan keberhasilan sistem informasi yang dihasilkan nantinya (Hanif Al Fatta, 2007:h. 44).

\section{c. Informasi}

Informasi dapat didefinisikan sebagai hasil dari pengolahan data dalam bentuk yang lebih berguna dan lebih berarti bagi penerimanya yang menggambarkan suatu kejadian - kejadian (event) yang nyata (fact) yang digunakan untuk pengambilan keputusan (Jogiyanto, 2007:h.692).

\section{METODOLOGI PENELITIAN}

Dalam penelitian ini metodologi penelitian yang digunakan adalah :

1. Tempat dan Waktu Penelitian

Penelitian ini dilakukan di PPAT Irma Rocha,

SH Dumai.

2. Jenis penelitian

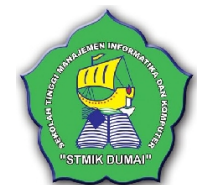

Jenis penelitian yang digunakan adalah metode deskriptif.

3. Teknik Analisa Data

Teknik analisa data yang digunakan dengan cara metode pengumpulan data yang digunakannya adalah sebagai berikut :

1. Riset Kepustakaan (library Research)

2. Metode ini dilakukan untuk pencarian data dengan membaca dan mempelajari berbagai buku-buku pengetahuan yang berhubungan dengan masalah yang diteleti.

3. Penelitian Lapangan (Field Research)

\section{HASIL DAN PEMBAHASAN}

a. Aliran Sistem Informasi (ASI) yang Baru

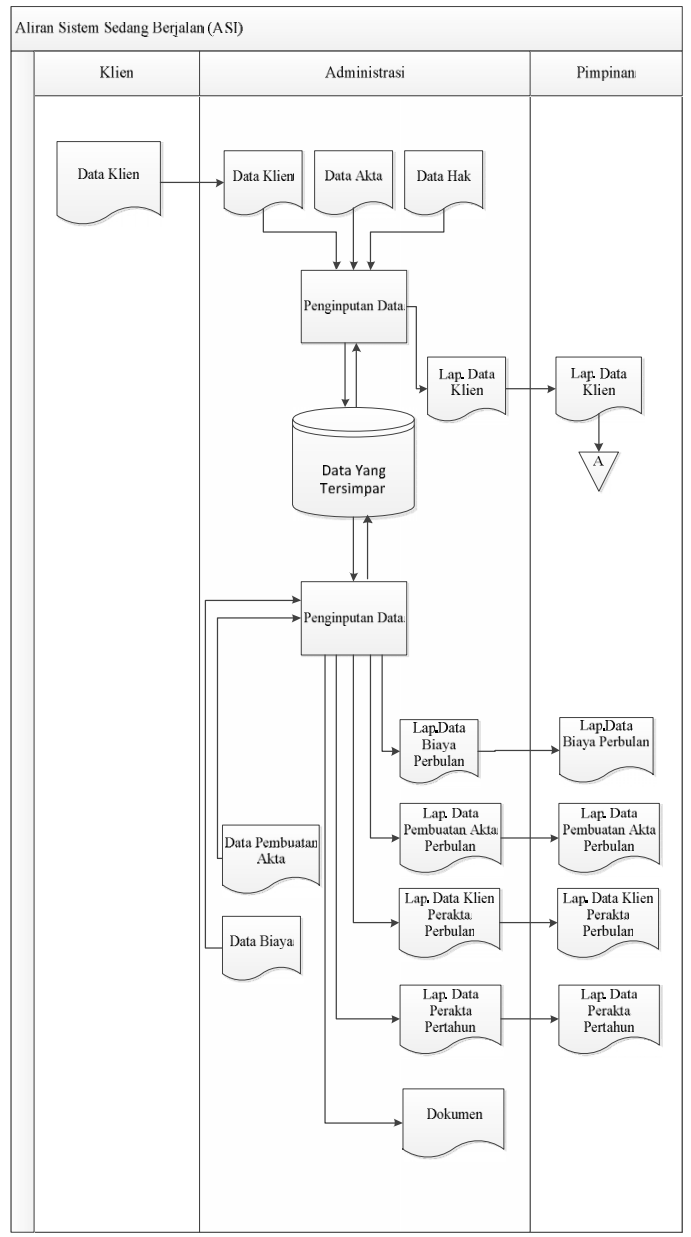

Gambar 1. Analisa Sistem Yang Baru

\section{b. Context Diagram}

Untuk menggambarkan hubungan sistem dengan entitas luarnya, dapat dilihat pada gambar Context Diagram dibawah ini : 
I NF ORM T I K

Jurnal Informatika, Manajemen dan Komputer, Vol. 8 No. 2 , Desember 2016

eISSN : 2580-3042

pISSN : 1979-0694

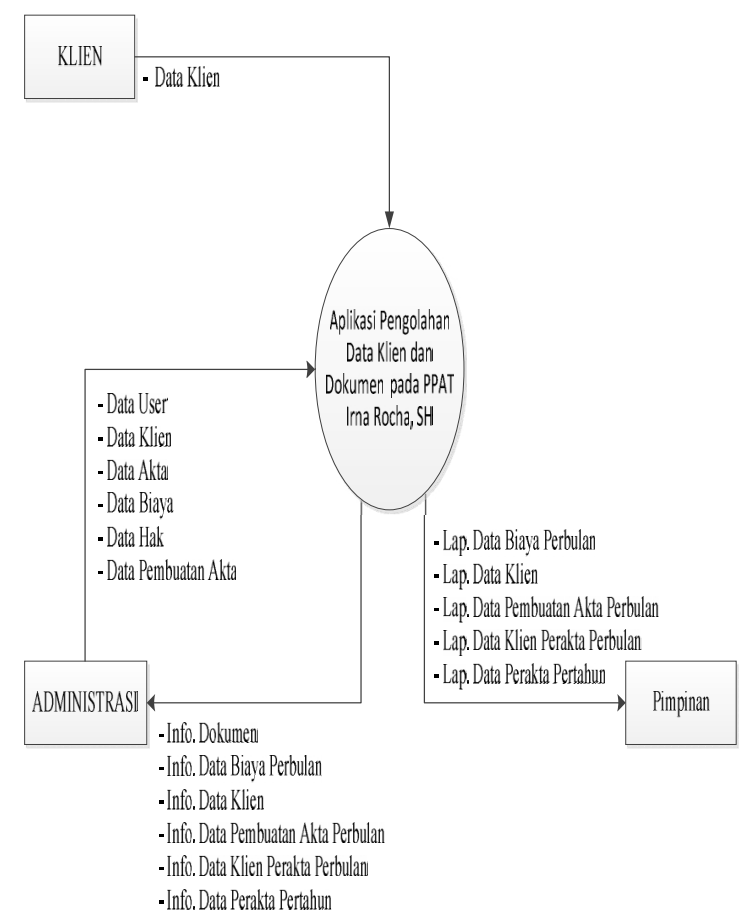

\section{Implementasi Sistem}

Form Login

Jalankan program aplikasi dengan cara mengklik icon program aplikasi (run). Setelah itu akan muncul Form Login. Masukkan User ID, Password. Jika setelah diisi dengan benar, maka program aplikasi utama terbuka.

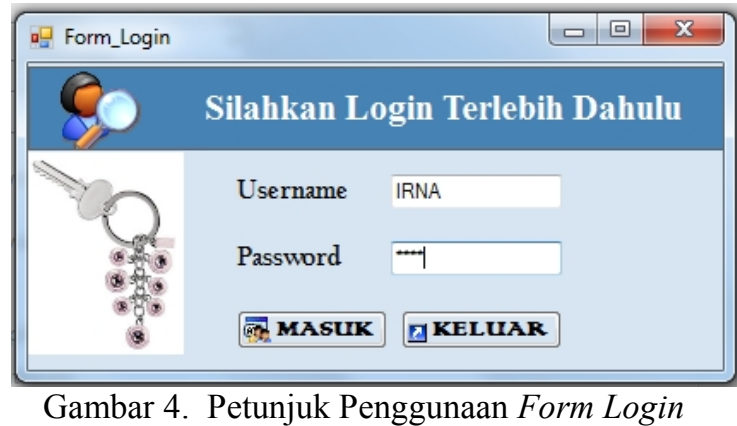

Gambar 4. Petunjuk Penggunaan Form Login

\section{Form Menu Utama}

Pada menu utama yang terdapat pada program, terdapat beberapa submenu yang memiliki fungsi dan kegunaan masing - masing. Klik submenu Data Master untuk menginput Data Klien, Data Akta, dan Data Hak. Klik submenu Data Transaksi untuk menginput Data Biaya dan Data Pembuatan Akta. Klik submenu Laporan untuk melihat Laporan Data Klien, Laporan Data Biaya Perbulan, Laporan Data Pembuatam Akta Perbulan dan Laporan Data Klien Perakta Perbulan. Klik submenu Data User untuk melakukan penambahan pengguna. Klik submenu Dokumen untuk melihat info dokumen. klik submenu pengesahan untuk melakukan penambahan pengesahan. Klik submenu keluar jika ingin keluar dari aplikasi.

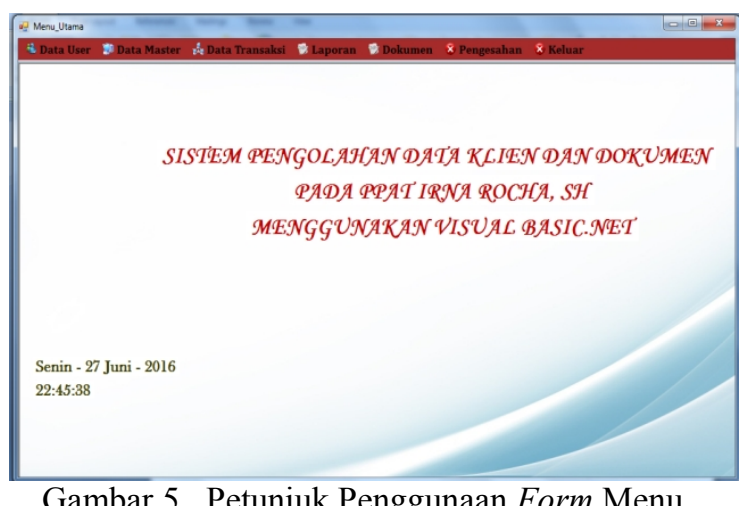

Gambar 5. Petunjuk Penggunaan Form Menu Utama

\section{Pengisian Data Master}

Data Master terdiri dari tiga bagian yaitu Data Klien, Data Akta dan Data Hak.

1. Data Klien

a. Pada menu utama, klik Data Master kemudian pilih Data Klien. 
I N F O R M A T I K

Jurnal Informatika, Manajemen dan Komputer, Vol. 8 No. 2 , Desember 2016

eISSN : 2580-3042

pISSN : 1979-0694

b. Isi Data Klien, setelah semua terinput maka klik tombol simpan untuk menyimpan data.

c. Jika Data Klien ada yang salah, maka masukkan kembali Kode Klien yang sudah diisi tadi maka secara otomatis akan tampil data - data yang lain, klik tombol ubah untuk mmengubah data. Klik tombol hapus untuk menghapus data.

d. Tombol batal dipilih untuk membatalkan data yang sedang diisi tetapi belum tersimpan ke database.

e. Untuk keluar dari Form Data Klien, klik tombol keluar untuk kembali ke Menu Utama.

\begin{tabular}{|c|c|c|c|c|}
\hline 口E Form_Input_Data_Klien & 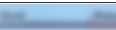 & 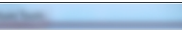 & - & 员回 \\
\hline Kode Klien & & & & \\
\hline Pihak Yang Nember & rikan & & & \\
\hline Nama & Mori Valentina & & & \\
\hline Alanat & Jl. Kelakap Tujuh & Gg.Koko & & \\
\hline NPWP & 0213130813 & & & \\
\hline No. Hp & 082383132114 & & & \\
\hline Pihalk Yang Menerin & & & & \\
\hline Nama & M. Hafizul Amin & & & \\
\hline Alamat & Jl. Takari No.59A & & & \\
\hline NPWP & 0213144393843 & & & \\
\hline No. $\mathrm{Hp}$ & 082174450199 & & & \\
\hline \begin{tabular}{|l|} 
SIMPAN \\
\end{tabular} & UBAH & \begin{tabular}{|l|l|} 
BATAL HAPUS \\
\end{tabular} & KELUAR & \\
\hline Kode_Klien & Nama_Pemberi & Alamat_Pemberi & NPWP_Pemberi & No_ $\mathrm{F}^{\mathbf{A}^{2}}$ \\
\hline $\mathrm{K} 16-002$ & Chairunnisa & Jl. Sudirman Gg. Bakti & 45678987654 & 08527 \\
\hline $\mathrm{K} \mathrm{K} 6-003$ & Liya Agustina & Jl Purnama & 986544354657 & $0852 t \equiv$ \\
\hline K16-004 & Ramadhani Fitrii & Jl. Sutomo & 23423974283 & $085377^{=}$ \\
\hline * & & & & 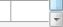 \\
\hline
\end{tabular}

Gambar 6. Petunjuk Penggunaan Form Data Klien

2. Data Akta

a. Pada menu utama, klik Data Master kemudian pilih Data Akta.

b. Isi Data Akta, setelah semua teriisi maka klik tombol simpan untuk menyimpan data.

c. Jika Data Akta ada yang salah, maka masukkan kembali Kode Akta yang sudah diisi tadi maka secara otomatis akan tampil data - data yang lain, klik tombol ubah untuk mmengubah data. Klik tombol hapus untuk menghapus data.

d. Tombol batal dipilih untuk membatalkan data yang sedang diisi tetapi belum tersimpan ke database.

e. Untuk keluar dari Form Data Akta, klik tombol keluar untuk kembali ke Menu Utama.

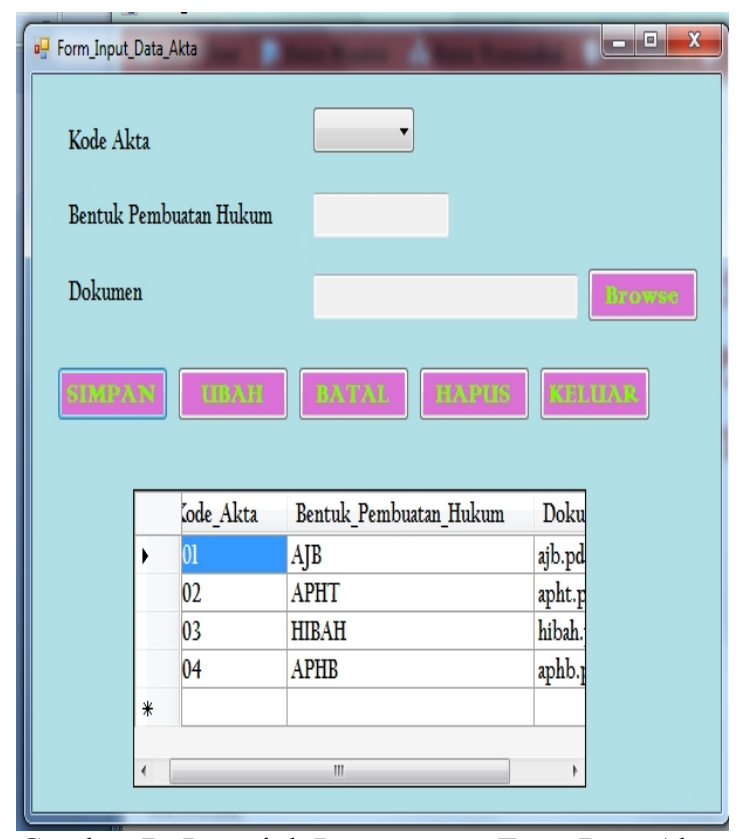

Gambar 7. Petunjuk Penggunaan Form Data Akta

3. Data Hak

a. Pada menu utama, klik Data Master kemudian pilih Data Hak.

b. Isi Data Hak, setelah semua teriisi maka klik tombol simpan untuk menyimpan data.

c. Jika Data Hak ada yang salah, maka masukkan kembali Kode Hak yang sudah diisi tadi maka secara otomatis akan tampil data - data yang lain, klik tombol ubah untuk mengubah data. Klik tombol hapus untuk menghapus data.

d. Tombol batal dipilih untuk membatalkan data yang sedang diisi tetapi belum tersimpan ke database.

e. Untuk keluar dari Form Data Hak, klik tombol keluar untuk kembali ke Menu Utama.

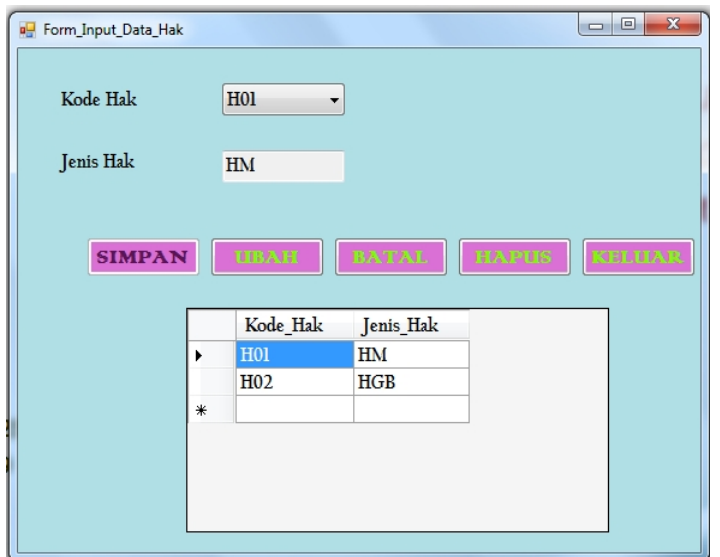

Gambar 8. Petunjuk Penggunaan Form Data Hak 
I N F ORM I T I K

Jurnal Informatika, Manajemen dan Komputer, Vol. 8 No. 2 , Desember 2016

eISSN : 2580-3042

pISSN : 1979-0694

\section{Pengisian Data Transaksi}

Data Transaksi terdiri dari dua bagian yaitu Data Pembuatan Akta, dan Data Biaya.

1. Data Pembuatan Akta

a. Pada menu utama, klik Data Transaksi kemudian pilih Data Pembuatan Akta.

b. Isi Data Pembuatan Akta, setelah semua teriisi maka klik tombol simpan untuk menyimpan data.

c. Jika Data Pembuatan Akta ada yang salah, maka masukkan kembali No.Urut yang sudah diisi tadi maka secara otomatis akan tampil data - data yang lain, klik tombol ubah untuk mengubah data. Klik tombol hapus untuk menghapus data.

d. Tombol batal dipilih untuk membatalkan data yang sedang diisi tetapi belum tersimpan ke database.

e. Untuk keluar dari Form Data Pembuatan Akta, klik tombol keluar untuk kembali ke Menu Utama.

Gambar 59. Petunjuk Penggunaan Form Data Pembuatan Akta

2. Data Biaya

a. Pada menu utama, klik Data Transaksi kemudian pilih Data Biaya.

b. Isi Data Biaya, setelah semua terisi maka klik tombol simpan untuk menyimpan data.

c. Jika Data Biaya ada yang salah, maka masukkan kembali Kode Biaya yang sudah diisi tadi maka secara otomatis akan tampil data - data yang lain, klik tombol ubah untuk mengubah data. Klik tombol hapus untuk menghapus data.

d. Tombol batal dipilih untuk membatalkan data yang sedang diisi tetapi belum tersimpan ke database.

e. Untuk keluar dari Form Data Biaya, klik tombol keluar untuk kembali ke Menu Utama.

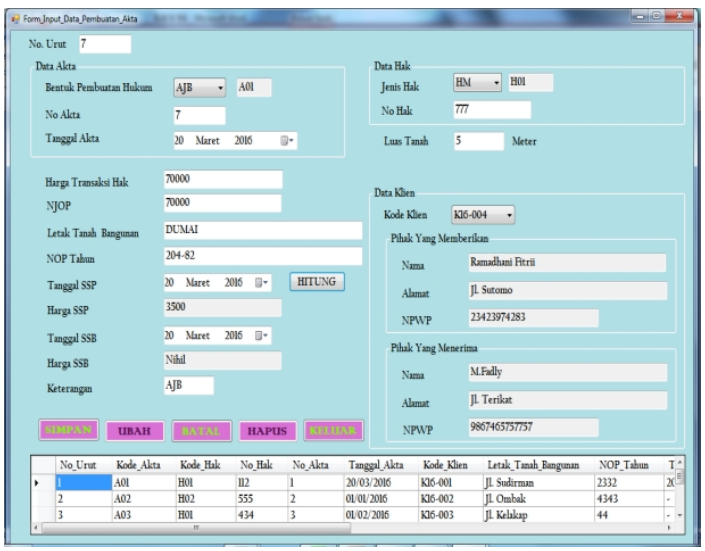

Gambar 9. Petunjuk Penggunaan Form Data Biaya

\section{KESIMPULAN}

Berdasarkan penelitian yang telah dilakukan dengan mengamati dan menganalisa sistem yang dibuat, maka dapat ditarik kesimpulan yaitu :

1. Pada aplikasi pengolahan data klien dan dokumen ini yang mana seluruh data klien dan pembuatan akta tersimpan dalam satu database.

2. Dengan adanya sistem komputerisasi ini pengguna akan mampu menyajikan informasi klien dan dokumen dengan cepat, selain itu dapat membuat laporan tepat pada waktunya

\section{REFERENSI}

Adi Nugroho. (2011). Perancangan Dan Implementasi Sistem Basis Data. Andi. Yogyakarta.

Agus Saputra, A.Md. (2011). Panduan Praktis Menguasai Database Server MySQL. PT Elex Media Komputindo. Jakarta.

Aswan. (2012). Kumpulan Program Kreatif Dengan Visual Basic.Net. Informatika Bandung. Bandung

Edi Winarno ST, et.al. (2013). Step by Step Visual Basic.NET. PT Elex Media Komputindo. Jakarta.

Ema Utami, Anggit Dwi Hartanto.(2012). Sistem Basis Data Menggunakan Microsoft SQL Server 2005. Andi.Yogyakarta

Fathansyah. (2012). Basis Data. Informatika Bandung .Bandung

Hanif Al Fatta. (2007). Analisa \& kPerancangan 
I N F O R M A T I K A

Jurnal Informatika, Manajemen dan Komputer, Vol. 8 No. 2 , Desember 2016

eISSN : 2580-3042

pISSN : 1979-0694

Sistem Informasi. Andi .Jogyakarta

Irnawan. (2011). Apapun Permintaannya, Crystal

Report Jawabannya. PT Elex Media

Komputindo. Jakarta.

Prof.Dr.Jogiyanto HM,MBA.,Akt. (2007).

Pengenalan Komputer. Andi Offset.

Yogyakarta.

(2009).

Analisis \& Desain Sistem Informasi. Andi Offset. Yogyakarta.

Tata Sutabri. (2012). Kosep Sistem Informasi. Andi. Yogyakarta.

Wahana Komputer. (2010). Membuat Aplikasi Client Server dengan Visual Basic 2008. Andi. Yogyakarta.

Wahana Komputer. (2014). Panduan Aplikatif \& Solusi (PAS) Sistem Informasi Penjualan Online untuk Tugas Akhir. Andi. Yogyakarta. 